\title{
De balans tussen regels en waarden
}

\section{Erik Mouthaan}

SAMENVATTING Een slechte formele governance is niet de belangrijkste oorzaak van de incidenten bij grote ondernemingen. Het is bovenal de menselijke factor die bepalend is voor de effectiviteit van het governance systeem. Ondernemingen zullen heel bewust en gestructureerd cultuur en ethiek binnen de organisatie moeten sturen. Dit roept nieuwe vragen op voor de toekomst. Hoe kun je integriteit en ethiek effectief sturen? In welke mate betekenen ethiek en cultuur een risico voor de verslaggeving en het handelen van een organisatie? Hoe is eigenlijk de cultuur binnen de onderneming, en welke rol speelt ethiek daarin? Meer grip op het sturen van ethiek en integriteit, betekent echter ook meer ruimte voor regelgevers om weer wat van de meest rigide governance regelgeving los te laten, en zo regels en waarden weer in balans te brengen.

\section{Inleiding}

In het afgelopen decennium is de wereld complexer en instabieler geworden. Er zijn niet alleen meer risico's, ze hebben ook een ander karakter gekregen. Tegelijkertijd lijkt het erop dat de maatschappij steeds minder risico's accepteert. Zeker na grote incidenten neemt de aversie tegen risico's toe. Overheden spelen daarop in en proberen de maatschappij te beschermen tegen de impact van incidenten bij grote ondernemingen. Dat heeft geleid tot allerlei nieuwe regelgeving over governance. Doel van die regelgeving is vooral om het beschadigde vertrouwen in de financiële markten te herstellen.

Oplossingen worden met name gezocht in toenemende transparantie. Belanghebbenden willen weten

Dr. Mr. E.H.J. Mouthaan RA is partner bij Deloitte en tevens als docent verbonden aan de Universiteit Leiden. wat er nu eigenlijk gebeurt binnen die organisaties. Welke belangen ze hebben, wat hun topmensen verdienen, hoe de controlemechanismen in elkaar zitten, welke risico's ze lopen en wat ze daaraan doen. De transparantie en de verslaggeving zijn juist op die punten enorm opgevoerd. Daarnaast is er veel aandacht voor de rol en de verantwoordelijkheden van de 'gatekeepers', en dan vooral de commissarissen, externe accountants en analisten. Zij waren het immers die hebben verzuimd in te grijpen bij de bekende (boekhoud)schandalen.

Hoewel de doelstelling van de nieuwe governanceregelgeving in de verschillende landen in grote mate vergelijkbaar is, zijn er wat betreft de uitwerking daarvan twee hoofdstromingen te onderscheiden; 'rules based'-wetgeving en 'principles basedzelfregulering, al dan niet wettelijk verankerd. De Amerikaanse Sarbanes Oxley Act (SOx) met vele honderden pagina's 'guidance' van de Securities and Exchange Commission (SEC) en de Public Companies Accounting Oversight Board (PCAOB), is een duidelijk voorbeeld van een 'rules based'-benadering. De eisen van SOx zijn strikte wettelijke voorschriften, gekoppeld aan zware straffen bij overtreding daarvan. In dit kader wordt wel gesproken van het 'complyor-die'-beginsel.

De Europese Commissie heeft zich, in tegenstelling tot de Amerikaanse benadering, nadrukkelijk uitgesproken voor 'principles based'-regelgeving (European Corporate Governance Forum, 2006). Europese codes als de Code-Tabaksblat en de Combined Code in de UK zijn daar dan ook goede voorbeelden van. Op grond van het 'comply or explain'-beginsel mag worden afgeweken van de in deze codes vastgelegde principes. Echter, op het moment dat een principe brede navolging geniet, en daarmee 'business practice' is geworden, moet een organisatie van goede huize komen om hier van af te wijken (Mouthaan, 2006). Dit kan feitelijk alleen als het betreffende principe evident niet relevant is voor 
de organisatie, danwel voldoende compenserende maatregelen getroffen zijn. Echt vrijblijvend zijn de codes dus zeker niet.

Via twee zeer verschillende benaderingen worden dezelfde primaire doelstellingen nagestreefd: bescherming van de maatschappij tegen de impact van incidenten bij grote ondernemingen, en herstel van het beschadigde vertrouwen in de financiële markten. Dit roept de vraag op of die doelstelling eigenlijk wel realistisch is. Dit artikel probeert op die vraag een antwoord te vinden door een analyse te maken van de achterliggende oorzaken van de bekende incidenten. In dit kader wordt in paragraaf 2 ingegaan op het zogenaamde 'Icarus effect' en het gedrag van 'zonnekoningen'. Vervolgens zal in paragraaf 3 de invloed van de focus op aandeelhouderswaarde en de verdeling van het aandelenbezit worden besproken, gevolgd door een analyse van falende 'gatekeepers' in paragraaf 4. Paragraaf 5 is geheel gewijd aan de Barings-case, die door de recente boekhoudschandalen wat op de achtergrond is geraakt, maar nog altijd uiterst relevant is. In tegenstelling tot wat vaak wordt aangenomen is de ondergang van Barings namelijk niet het gevolg van één werknemer, Nick Leeson, die het systeem lange tijd wist te omzeilen. De problemen bij Barings zaten diep in de cultuur van de organisatie en die culturele aspecten bleken zwaarder te wegen dan de formele governance. Conclusies ten aanzien van de centrale vraagstelling, tenslotte, zijn opgenomen in paragraaf 6 .

\section{Het Icarus effect en zonnekoningen}

De huidige Amerikaanse corporate governanceregelgeving heeft zich ontwikkeld in een drietal golfbewegingen, elk volgend op een grote crisis; de eerste na de 'panic of 1873' die ontstond na het instorten van het zakenimperium van Jay Cooke, de tweede na de beurskrach in 1929 en het instorten van het imperium van Samuel Insull in 1932, en de derde na het omvallen van Enron en WorldCom in 2002 (Skeel, 2005).

Bij de incidenten rondom Jay Cooke speelde onder meer een overnamestrijd om Erie Railroad, waarbij sprake was van corruptie en het op grote schaal handelen met voorkennis door betrokken managers. Samuel Insull was een 'business superstar' die in de jaren '20 van de vorige eeuw in hoog tempo (energie)bedrijven opkocht in de VS. De wankele basis voor de financiering van al die transacties werd verhuld door een ondoorzichtige structuur van (hold ing)vennootschappen. De Securities Acts van 1933 en 1934 volgden op de beurskrach van 1929 en de ondergang van Insull's imperium, die vergelijkbaar was met de ondergang van Enron. De Securities Acts introduceerden onder meer nieuwe disclosurevereisten, antifraude bepalingen en de Securities and Exchange Commission (SEC) als toezichthouder. In reactie op het omvallen van Enron en WorldCom is de Sarbanes Oxley Act ingevoerd, die vooral eisen stelt aan het functioneren en de verantwoordelijkheden van de bestuurders en de belangrijkste gatekeepers: non-executives, auditors en analisten en de transparantie vergroot door aanvullende disclosurevereisten.

Het is vooral dit harde en gerichte overheidsingrijpen, in combinatie met het scherpe toezicht door de SEC, dat zelfregulering in de VS feitelijk onmogelijk heeft gemaakt. De enige uitzondering hierop is de 'principles based'-regelgeving rondom zorgvuldigheidsnormen die door de Delaware Court worden gehanteerd voor bestuurders en managers, de zogenaamde 'fiduciary duties', en de 'business judgment rule' die ervoor zorgt dat bestuurders en managers niet aansprakelijk zijn voor besluiten die 'te goeder trouw' zijn genomen (Mouthaan, 2000).

Overigens staat SOx de laatste tijd behoorlijk onder druk. Zo wil de Amerikaanse minister van Financiën, Henry Paulson, het toezicht op de financiële markten herzien. Volgens Paulson is de bescherming van beleggers niet in evenwicht met de kosten voor het bedrijfsleven. Ook het Comittee on Capital Markets Regulation pleit voor een afzwakking van de Amerikaanse beursregels (Committee on Capital Markets Regulation, 2006). Het comité vreest dat door de strenge wetgeving bedrijven een beursnotering buiten de Verenigde Staten nemen. In 2006 waren de beurzen van Hongkong en Londen volgens de commissie aanzienlijk succesvoller in het aantrekken van nieuwe fondsen. In een poging om de kosten meer in balans te brengen met de voordelen van SOx heeft de SEC begin 2007 guidance uitgebracht voor de evaluatie van de interne beheersing door het management (SEC release nrs. 33-8762 en 33-8809). In deze guidance staat een top-down, risicogerichte, benadering centraal. Bovendien heeft de PCAOB de guidance voor auditors overeenkomstig aangepast en tevens een nieuwe standaard inzake 'integrated audits' uitgebracht (PCAOB, Auditing Standard no. 5). De nieuwe standaard moet vooral leiden tot een betere integratie met de werkzaamheden uit hoofde van de jaarrekeningcontrole en efficiënter gebruik van de werkzaamheden van anderen, zoals interne accountants.

Skeel (2005) heeft Amerikaanse incidenten geanalyseerd en concludeerde dat een drietal algemene 
factoren aan de basis stond van al die incidenten. Hij spreekt in dat kader over het 'Icarus effect', naar de Griekse mythologie waarin Icarus vleugels van was en veren kreeg van zijn vader. Hoewel hij door zijn vader was gewaarschuwd niet te dicht bij de zon te vliegen, kon Icarus het niet laten steeds hoger en hoger te gaan, tot de zon de was deed smelten en Icarus neerstortte. De drie factoren die het Icarus effect veroorzaken zijn; 'risktaking', 'competition', en 'manipulation of the corporate form'.

- 'Risk taking.' Om de top te bereiken heeft een CEO in zijn carrière risico's moeten nemen. Daardoor is hij in het algemeen zelfbewust en ook genegen om risico's te nemen. Het nemen van risico's wordt bovendien aangemoedigd door beloning in opties. Die kennen immers alleen 'upside' en geen 'downside'; als de koers omlaag gaat heeft dat geen gevolgen voor de beloning, terwijl een koerstijging heel lucratief kan zijn.

- 'Competition'. Succes trekt bovendien concurrentie aan, zolang er tenminste geen grote drempels zijn om toe te treden tot de markt. Die toenemende concurrentie kan er toe leiden dat nog grotere risico's moeten worden genomen om eerdere successen te herhalen.

- 'Manipulation of the corporate form'. Een complexe organisatiestructuur, tenslotte, maakt het gemakkelijker om cijfers te manipuleren. Skeel heeft het in dit kader over 'corporate smoke and mirrors', resulterend in boekhoudschandalen als bij Cook, Insull, Enron en WorldCom.

Ook Cools zoekt de oorzaak van de bekende schandalen niet in slechte formele corporate governance (Cools, 2005). Hij noemt excessieve variabele Beloning, het afgeven van irrealistische targets en 'zonnekoningengedrag' van CEO's als de drie belangrijkste oorzaken van (boekhoud)schandalen. Cools heeft de publieke reputatie en de populariteit van managers gemeten aan de hand van citaten van CEO's in de zakelijke en populaire pers gedurende de vijf jaren voorafgaand aan het jaar waarin een fraude aan het licht kwam. Op basis van dit onderzoek concludeert hij dat bij de frauderende bedrijven vaak sprake is van 'gevierde helden', CEO's met een buitensporig grote populariteit in het zakenleven en daarbuiten; de 'zonnekoningen'. Het grootste probleem van die zonnekoningen is dat ze geen tegenspraak dulden, aldus Cools. Daardoor verdwijnen de 'checks and balances' en wordt de macht niet langer gecontroleerd. Narcistische leiders zouden bovendien hun gevoel voor grenzen verliezen waardoor ze uiteindelijk, net als Icarus, te dicht bij de zon vliegen.

\section{De invloed van aandeelhouderswaarde en de 3 verdeling van het aandelenbezit}

Een andere invalshoek komt van Deakin en Konzelmann (2003). Zij noemen de extreme aandacht voor aandeelhouderswaarde, en in het verlengde daarvan de beurskoers van de onderneming, als de belangrijkste oorzaak van de incidenten bij vooral Amerikaanse ondernemingen (Deakin en Konzelmann, 2003). Focus op aandeelhouderswaarde werd in het begin van de jaren ' 80 door financieel economen gezien als de manier om de 'agencykosten', het gevolg van de scheiding van eigendom en bestuur, te minimaliseren. Door aandeelhouderswaarde centraal te stellen in de strategie van de onderneming en in de beloning van de bestuurders, zouden de belangen van aandeelhouders en management immers parallel gaan lopen. De golf van vijandige overnames in de jaren ' 80 en de toenemende invloed van institutionele investeerders in de jaren '90 zorgden er voor dat aandeelhouderswaarde een centrale plaats kreeg in de governance-systemen van vooral de Angelsaksische landen. Gevolg van die centrale plaats voor aandeelhouderswaarde was ook de introductie van aandelenopties in de beloning van bestuurders. Dit werd met name door institutionele beleggers gezien als een goede manier om de belangen van bestuurders en aandeelhouders gelijk te trekken. De ondergang van Enron zien Deakin en Konzelmann als het (onvermijdbare) gevolg van dit primaat van de aandeelhouderswaarde. De druk om aandeelhouderswaarde te genereren was bij Enron immers extreem, vooral door de grote hoeveelheden aandelenopties die waren toegekend aan managers. Dit resulteerde in een uiterst agressieve expansie die uiteindelijk de ondergang van Enron betekende.

Naast het primaat van de aandeelhouderswaarde speelt ook de verdeling van het aandelenbezit een belangrijke rol bij (boekhoud)schandalen. Coffee maakt in dit kader onderscheid tussen 'dispersed ownership systems' en 'concentrated ownership systems' (Coffee, 2005). In een dispersed ownership system is er sprake van een sterke effectenmarkt, hoge verslaggevingstandaarden, grote handelsvolumes, een hoge mate van transparantie en een disciplinerende werking van de markt. Kenmerken van een 'concentrated ownership system' zijn de aanwezigheid van controlerende (meerderheids-)aandeelhouders, een zwakkere markt en minder transparantie. Het verschil tussen beide systemen is vooral van belang voor het soort fraude. Daarbij is het niet zonder meer mogelijk om een directe relatie te leggen tussen de verdeling van het aandelenbezit en de vorm van de regelgeving: 
'principles based' of 'rules based'. Binnen een bepaalde markt of jurisdictie komen immers vaak beide systemen voor.

In een 'dispersed ownership system' zijn het vooral de managers die, mede gedreven door een hoge beloning in aandelenopties, de resultaten manipuleren. Dit gaat uiteindelijk ten koste van de aandeelhouders. Onderzoek van het US General Accounting Office (GAO, 2006) en de Huron Consulting Group (Huron Consulting Group, 2005) laat zien dat het aantal herzieningen van kwartaalcijfers en jaarcijfers door Amerikaanse beursgenoteerde ondernemingen vanaf de tweede helft van de jaren '90 explosief is gestegen. In 1990 waren dat er volgens het GAO nog 33, oplopend naar 50 in 1995. Na 1995 neemt het aantal zeer sterk toe; 170 in 1999, 225 in 2001, 308 in 2003 en 523 in de eerste negen maanden van 2005. De gevolgen van een restatement zijn aanzienlijk; gemiddeld 10 procent koersverlies in een periode van drie dagen, en 25 procent over een periode van 120 dagen rondom de aankondiging (Coffee, 2005).

Veruit de belangrijkste oorzaak van de restatements in de VS is een bijstelling van de gerapporteerde omzet (GAO, 2006). Coffee concludeert hieruit dat managers toekomstige omzet hebben 'gestolen' om een niet-realistische groei te laten zien, en daarmee aan de hooggespannen verwachtingen van de markt te voldoen, of deze zelfs te overtreffen. Als oorzaak hiervan ziet hij de ontwikkelingen in de beloning van managers in de VS. Mede onder invloed van de hiervoor besproken focus op aandeelhouderswaarde en Amerikaanse belastingwetgeving, nam de aandeelgerelateerde beloning van managers in de jaren ' 90 enorm toe. In 1990 was de gemiddelde beloning van een S\&P 500 CEO nog \$1,25 miljoen, waarvan 92 procent in cash en 8 procent in aandelen. In 2001 was niet alleen de absolute hoogte van dit gemiddelde sterk toegenomen, ook de verhouding tussen cash en aandelen was omgedraaid. De gemiddelde beloning lag inmiddels boven $\$ 6$ miljoen, waarvan 66 procent in aandelen.

Verscheidene onderzoekers hebben een sterke correlatie aangetoond tussen een hogere beloning in aandelen en het manipuleren van cijfers (Efendi, Srivastava en Swanson, 2007; en Denis, Hanouna en Sarin, 2006). Nu price-to-earnings ratio's een belangrijke rol spelen bij de waardering van aandelen is de verleiding kennelijk groot om de beurskoers te manipuleren door nog niet gerealiseerde omzet mee te nemen in de cijfers.

Het manipuleren van de beurskoers, als in 'dispersed ownership systems', speelt een ondergeschikte rol bij fraudes in een 'concentrated ownership system'.
Daar zal eerder sprake zijn van machtsmisbruik en belangenverstrengeling, vooral in 'related-party transactions', door de controlerende aandeelhouder, wat ten koste gaat van de minderheidsaandeelhouders. De Parmalat-case is een voorbeeld van fraude in een 'concentrated ownership system'. In totaal is bij Parmalat, over een periode van zo'n tien jaar, ruim 2 miljard euro onttrokken middels transacties waarbij aandeelhouders met een controlerend belang, de Tanzi-familie, waren betrokken.

\section{De gatekeepers}

Ferrarini en Giudici (2005) hebben de Parmalatfraude in detail geanalyseerd en concluderen dat deze niet te wijten was aan gebrekkige wet- en regelgeving. Het probleem lag volgens hen veel meer bij gebrekkig toezicht. Zo was lange tijd onduidelijk welke onafhankelijke 'non-executive directors' er in de board van Parmalat zaten. Dit zouden er volgens de jaarrekening 12 zijn, op een totale board bestaande uit 14 directors. Toen in 2003 de namen van de leden van de board bekend werden was echter onmiddellijk duidelijk dat er feitelijk geen onafhankelijke nonexecutives waren. Dit was in strijd met de Italiaanse corporate governance-code (op 'comply or explain' basis) die de benoeming van onafhankelijke nonexecutives voorschrijft. Hoewel Parmalat niet voldeed aan die eis, en dit niet in haar corporate governanceverslag vermeldde, werd niet door de beursautoriteiten ingegrepen. Omdat er geen onafhankelijke non-executive directors waren, is bij Parmalat nooit sprake geweest van enig onafhankelijk toezicht op de management board. De externe accountants zijn bovendien, tot het ontdekken van de fraude, niet in staat gebleken dit gebrek aan toezicht te compenseren. Een tweetal accountants zou zelfs actief aan de fraude hebben meegewerkt. Tenslotte bleken ook banken en juristen die meewerkten aan aandelenemissies van Parmalat niet in staat om de problemen bij Parmalat aan het licht te brengen.

Falende toezichthouders spelen een rol bij fraudes in zowel 'dispersed ownership systems' als in 'concentrated ownership systems'. Van traditionele gatekeepers als commissarissen, of non-executives en externe accountants, maar ook analisten, kredietbeoordelaars en (investment)banken wordt verwacht dat zij signaleren als het mis dreigt te gaan met een onderneming. In werkelijkheid blijken deze toezichthouders echter lang niet altijd onafhankelijk te zijn van het (schijnbare) succes van de onderneming, en verzaken zij daardoor maatregelen te treffen. Toch is uit onderzoek gebleken dat er wel degelijk signalen waren dat 
er een restatement, en dus een koerscorrectie, aan zat te komen. Vooral zogenaamde 'short sellers' op de aandelenmarkt hebben hiervan geprofiteerd (Griffin, 2002; Desai et al., 2004). Cools (2005) concludeert onder meer dat in tijden van oplopende beurskoersen blijkbaar te weinig vragen worden gesteld door commissarissen, accountants, analisten en aandeelhouders. Hij spreekt in dit kader ook over het dilemma van de succesvolle CEO, die zijn presidentcommissaris, CFO en zelfs 'moeder de vrouw' ontstijgt. De CEO ontglipt aan controle en het machtsevenwicht gaat daardoor wankelen, aldus Cools.

5

\section{De Barings-case}

Onderstaand volgt een gedetailleerde analyse van de Barings-case, gebaseerd op het openbare rapport van de overheid van Singapore (Singapore Government, 1995). De Barings Group ging in 1995 ten onder als het directe gevolg van malversaties door Nick Leeson, één van haar handelaren. Leeson had, door ongeautoriseerde transacties op de derivatenmarkt in het Verre Oosten, een verlies veroorzaakt van zo'n 850 miljoen Engelse Pond. In tegenstelling tot wat vaak wordt aangenomen is de ondergang van Barings echter niet hoofdzakelijk te wijten aan die ene werknemer, Nick Leeson, die het systeem lange tijd wist te omzeilen. De problemen bij Barings zaten immers veel dieper, in de cultuur van de organisatie. Die culturele aspecten bleken zwaarder te wegen dan de formele governance.

Leeson kwam in 1989 in dienst bij Barings Securities Ltd (BSL) en begin 1992 diende hij een aanvraag in voor registratie als 'dealer' bij de Securities and Futures Authority (SFA) in Engeland. Het SFA ontdekte dat Leeson een valse verklaring had gegeven over openstaande privé-schulden en stelde daaromtrent vragen aan BSL, waarop BSL de aanvraag introk. In april 1992 werd Leeson overgeplaatst naar Barings Futures in Singapore (BFS), waar hij, ondanks de problemen met de SFA, werd belast met de handel in 'futures'. Leeson werd floor-manager voor BFS bij SIMEX, de beurs in Singapore. De problemen met de SFA waren niet gemeld aan SIMEX.

De rol die Leeson in Singapore vervulde veranderde met de tijd. Oorspronkelijk handelde hij in opdracht van externe cliënten van andere Barings-maatschappijen ('agency trading'), later ging hij steeds meer voor risico van BFS handelen ('proprietary trading'). Tegen het eind van 1994 was Leeson verantwoordelijk voor een aanzienlijk deel van de winst van de Barings Group. Leesons activiteiten betroffen primair arbitrage, transacties waarbij gebruik werd gemaakt van prijsverschillen tussen SIMEX en de Tokyo of Osaka Stock Exchange. Daarbij was het Leeson uitsluitend toegestaan gedurende een werkdag (gelimiteerde) ongedekte posities in te nemen. Dit soort transacties kent normaal gesproken relatief weinig risico en daardoor lage marges.

Vrijwel vanaf het begin van zijn handelen aan de SIMEX maakte Leeson gebruik van de door hem geopende 'account 88888'. De transacties die op de rekening 88888 werden geboekt betroffen zeer hoge, ongedekte, posities waarop verliezen werden geleden. De transacties werden overgeboekt van andere rekeningen van de Barings Group, waarbij op die rekeningen dan vaak kunstmatige winsten ontstonden. Gezien de aard en omvang van de posities op account 88888 zouden zelfs kleine marktbewegingen tot enorme verliezen kunnen leiden. Toen dit begin 1995 ook daadwerkelijk gebeurde, betekende dit de val van de gehele Barings Group.

Leeson had uiteraard middelen nodig om de verliezen en ongedekte posities ('margin deposits') van de 88888-transacties te financieren. Deze middelen kwamen van andere Barings-maatschappijen. Vlak voor de val van Barings in februari 1995 had Leeson in totaal zo'n \$1,7 miljard van de Barings Group verkregen, zonder daarover verantwoording af te leggen. In het rapport van de Singaporese overheid worden enkele factoren genoemd die hieraan hebben bijgedragen.

Ten eerste onderging Barings destijds een reorganisatie, waarbij de Barings Investment Bank Group werd gevormd, die verantwoordelijk werd voor de activiteiten van Barings op het gebied van banking en securities. Bovendien bleek de matrixmanagementstructuur van Barings in de praktijk niet te werken. Leeson werd geacht te rapporteren aan het lokale management van Barings Futures Singapore en aan het productmanagement in Londen. Het lokale management ging er echter van uit dat Leeson verantwoordelijk was voor zijn eigen activiteiten en oefende daar geen toezicht op uit, terwijl het productmanagement in Londen zich op het standpunt stelde dat primair het lokale management verantwoordelijk was. Zo kon Leeson ongestoord zijn gang gaan, ondanks een rapport van Barings Internal Audit uit het derde kwartaal van 1994, waarin werd gesignaleerd dat Leeson de leiding had over zowel front- als backoffice activiteiten. Leeson kon daardoor niet alleen vrij handelen, maar ook het administratieve traject beïnvloeden en zo zijn fouten maskeren. In het rapport was overigens ook opgenomen dat het lokale management correctieve maatregelen zou nemen, deze maatregelen zijn echter nooit geïmplementeerd. 
Naast het falende toezicht in de matrixstructuur bleek ook het toezicht door het Asset \& Liability Committee (ALCO) niet effectief. ALCO was verantwoordelijk voor het toezicht op risicovolle posities, handelslimieten, handelsresultaten en de allocatie van middelen. De hoge bedragen die aan BFS werden verstrekt hadden ALCO tot nader onderzoek aan moeten zetten. Vaststaat echter alleen dat er een aantal besprekingen is geweest in januari en februari 1995 teneinde het verstrekken van middelen aan Leeson te structureren. Wel heeft ALCO op een gegeven moment de beslissing genomen om Leeson te vragen zijn posities terug te brengen, zo ver is het echter nooit gekomen. Ook de afdeling Financial Controls faalde in zijn toezicht. Deze afdeling had het bestaan van de rekening 88888 moeten ontdekken. Het management van deze afdeling was echter van mening dat haar taak niet verder ging dan het verstrekken van informatie aan de verantwoordelijke managers. Financial Controls heeft de financiering van Leesons activiteiten nooit adequaat nagetrokken, aldus de rapporteurs. Toen de afdeling eind 1994 probeerde deze financieringsstromen in kaart te brengen, bleek dit een complexe exercitie te zijn, die nooit is afgerond. Sommige van de middelen die Leeson gebruikte voor 88888-transacties kwamen van BSL, waar Leeson zijn carrière bij Barings was begonnen. Bij BSL waren deze gelden verantwoord als 'loans to clients'. Van de afdeling Credit Control mocht dan ook worden verwacht dat de kredietwaardigheid van deze cliënten werd onderzocht, waarbij dan duidelijk zou zijn geworden dat er helemaal geen cliënten waren. Zo'n onderzoek heeft echter nooit plaatsgevonden.

Het productmanagement in Londen aanvaardde de door Leeson gerapporteerde hoge winsten zonder meer. Dit terwijl toch normaal gesproken de marges op de arbitrageactiviteiten, zoals die van Leeson, relatief laag zijn. Ook hier had het initiatief tot nader onderzoek genomen moeten worden.

Leeson heeft voortdurend onjuist gerapporteerd over de door hem afgesloten transacties, waarbij de 'exposure’ van de Barings Group veel te laag werd voorgesteld. Desondanks overschreden de gerapporteerde posities ruim de door de Bank of England gestelde limieten. Eind 1994 overschreed de totale exposure zelfs de assets van de Barings Group met zo'n 75 procent. Zowel de Bank of England als het senior management van Barings verzuimde echter resoluut in te grijpen, omdat er onduidelijkheid bestond over de definitie van de limieten. Bovendien had de Bank of England eerder ook niet ingegrepen en kreeg het senior management van de Barings Group daarom tijd om de zaken op orde te brengen.
Ondanks dat het senior management van Barings ontkent op de hoogte te zijn geweest van het bestaan van rekening 88888 , zijn de rapporteurs van mening dat het management tenminste hiervan op de hoogte had moeten zijn, en wel om de volgende redenen:

- de financiering van Leesons activiteiten kwam hoofdzakelijk van andere Barings-maatschappijen. Leeson had beperkt andere mogelijkheden om aan geld te komen;

- sinds 1993 wist BSL dat er een onbalans was tussen de verstrekte gelden en gerapporteerde transacties door afdelingen in het Verre Oosten, in de loop van 1994 werd duidelijk dat de problemen ontstonden in Singapore, bij BFS. Een afdoende verklaring werd echter niet gevonden, terwijl het geregistreerde tekort begin 1995 snel opliep tot 320 miljoen Engelse Pond (eind 1994100 miljoen Engelse Pond);

- hoewel Leeson de 88888-transacties buiten de tradinginformatie ('trading feed') had gehouden, was de volledige informatie ten aanzien van margin requirements ('margin feed') beschikbaar, waarin alle transacties voorkwamen. Dit document, van één pagina, had de tekorten direct kunnen lokaliseren; en

- Internal Audit had in het derde kwartaal van 1994 al gerapporteerd dat Leeson te veel macht had, omdat hij de leiding had over zowel het front- als het backoffice. Leeson was daardoor in staat zijn eigen transacties te verantwoorden zoals hij dat wilde. Overigens merkte Internal Audit in haar rapport op dat de risico's van Leesons positie werden beperkt doordat elders binnen de groep controles, vooral de diverse aansluitingen, werden uitgevoerd, omdat de financiering van andere Barings-maatschappijen kwam. Zoals inmiddels bekend is, werkten deze controles niet.

In januari 1995 deed SIMEX navraag naar de posities van BFS, daarbij werd specifiek verwezen naar transacties op rekening 88888 . BFS reageerde daarop met een tweetal brieven, de eerste was opgesteld door Leeson zelf, maar verzonden door de financieel directeur van BFS, de tweede was opgesteld door de group treasurer van Barings en goedgekeurd door ALCO. In beide brieven werd verzekerd dat BFS haar verplichtingen zou nakomen.

Op de datum van de tweede brief, 10 februari 1995, was echter bij ALCO al bekend dat de middelen die BFS opvroeg uit hoofde van cliëntenposities, niet aansloten op de door BSL gerapporteerde ontvangsten van cliënten en dat Leeson zijn posities nog niet had teruggebracht. Desondanks gaf ALCO, zonder nader onderzoek, haar goedkeuring aan de tot SIMEX gerichte verklaring. Bovendien verstrekten Barings companies in de weken daarna opnieuw zo'n $\$ 1,1$ miljard aan BFS. 
Bij de controle van de jaarrekening van BFS in januari 1995 door de externe accountant, Coopers \& Lybrand, kwam een verschil naar voren tussen de Yen-rekening volgens de administratie van BFS en een opgave van SIMEX, van zo'n S\$ 115 miljoen. Leeson kon dit verschil eerst niet verklaren en stelde dat het een transactie betrof waarbij BFS had bemiddeld. Toen deze verklaring, op verzoek van de financieel directeur van Barings, nader werd onderzocht, bleek het uiteindelijk om een ongeautoriseerde transactie van Leeson te gaan.

De Chief Executive Officer van Barings, Norris, ontmoedigde echter elk onafhankelijk onderzoek naar de omstandigheden waaronder deze transactie had plaatsgevonden. Bovendien nam Norris stappen om het feit voor de overige boardleden en het ALCO verborgen te houden, en oefende hij druk uit op Coopers \& Lybrand om het buiten de management letter te houden. Toen op 8 februari toch discussie in de ALCO-meeting volgde, stelde Norris dat het om een operationele of een boekingsfout ging. Norris verzuimde ook correctieve maatregelen ten opzicht van Leeson te nemen. In plaats daarvan ontving deze een aanzienlijke bonus over 1994 en werd het Leeson zelfs toegestaan zijn posities te vergroten. De rapporteurs merken daarbij op dat Norris er belang bij had om de verliezen van rekening 88888 buiten de toch al tegenvallende resultaten van de bank te houden.

Op 17 februari 1995, één week voor de val van de Barings Group, werd opnieuw een tekort ontdekt bij BFS, nu van \$ 215 miljoen, en startte Group Treasury een onderzoek naar de reden voor Leesons aanvragen voor additionele financiering, terwijl hij toch zijn positie zou afbouwen. Bovendien liet SIMEX weten actie tegen BFS te ondernemen in verband met schending van de beursregels. Onder deze omstandigheden vluchtte Leeson in de nacht van 23 februari 1995 uit Singapore, met achterlating van een totaal van $\$ 2,2$ miljard aan verliezen.

De Barings-case maakt bovenal duidelijk dat de menselijke factor uiteindelijk bepalend is voor de effectiviteit van het governance-systeem, hoe goed die structuur in opzet ook is. Binnen Barings werden, door de gehele organisatie heen, structureel verantwoordelijkheden ontweken, signalen genegeerd, essentiële controlemaatregelen niet uitgevoerd, corrigerende maatregelen niet genomen, kritische vragen niet gesteld en zelfs fouten toegedekt. Dit ondanks dat in opzet voldoende maatregelen waren getroffen om een fraude als die door Leeson te voorkomen, en bovendien binnen een organisatie die zich terdege bewust moet zijn geweest van het reputatierisico van interne fraude. Culturele aspecten bleken echter zwaarder te wegen dan formele governance.

\section{Conclusies}

De in dit artikel besproken onderzoeken en de Baringscase maken laten zien dat een slechte formele governance niet de belangrijkste oorzaak is van de incidenten bij grote ondernemingen. Het is bovenal de menselijke factor die bepalend is voor de effectiviteit van het governance-systeem. Normen en regels horen in die zin bij elkaar. Het voldoen aan de recente corporate governance regelgeving is weliswaar een voorwaarde voor 'good governance' maar biedt daarvoor zeker geen garantie.

Aanvullend zullen ondernemingen heel bewust en gestructureerd cultuur en ethiek binnen de organisatie moeten sturen. Morris Tabaksblat noemt in dit kader rituelen en tradities als bindende elementen voor een organisatie (Couwenberg en Haenen, 2007). Cools concludeert dat de als gevolg van de recente regelgeving toegenomen control het sturen op vertrouwen tegelijk mogelijk en noodzakelijk maakt. Hij roept ondernemingen op om te werken aan 'gedeelde overtuigingen', gebaseerd op respect, vertrouwen, samenwerking en ambitie, en te voorkomen dat zonnekoningen de top bereiken (Cools, 2005). Ook Skeel doet vergelijkbare aanbevelingen. Daarbij benadrukt hij dat alleen het opstellen van een Code of Ethics de cultuur en ethiek binnen een organisatie niet zal veranderen; "only if the company's values are reflected in the executive suite and in the expectations created throughout the firm will the recent emphasis on ethics prove more than a temporary fad" (Skeel, 2005).

De constatering dat regels alleen niet voldoende zijn om incidenten te voorkomen roept nieuwe vragen op voor de toekomst. Hoe stuur je op normen en cultuur binnen een organisatie? Hoe kun je integriteit en ethiek managen? Gatekeepers zullen zich moeten afvragen in welke mate ethiek en cultuur een risico inhouden voor de verslaggeving en het handelen van een organisatie. Bovendien zullen ze wegen moeten vinden om vast te stellen wat nu eigenlijk de cultuur van de onderneming is, en welke rol ethiek daarin speelt. Iedereen zal ook zijn eigen functioneren tegen het licht moeten houden. Over dit deelgebied van governance is nog relatief weinig bekend, en het laat zich lastig in harde regels vastleggen. Bovendien vereist het betrokkenheid van andere dan de traditionele disciplines. Vooral gedragsdeskundigen zullen een belangrijke bijdrage kunnen leveren aan de ontwikkelingen in deze discipline. Meer grip op het sturen van ethiek en integriteit, betekent echter ook meer ruimte voor regelgevers om weer wat van de meest rigide governance-regelgeving los te laten, en zo regels en waarden weer in balans te brengen. 


\section{Literatuur}

Coffee, Jr., J.C. (2005), A theory of corporate scandals: why the US and Europe differ, Oxford Review of Economic Policy, vol. 21, no. 2, pp. 198-211.

Committee on Capital Markets Regulation (2006), Interim Report Committee on Capital Markets Regulation, 30 november 2006; zie: www.capmktsreg.org/.

Cools, K. (2005), Controle is goed, vertrouwen nog beter. Over bestuurders en corporate governance, Assen: Van Gorcum.

Couwenberg, P., en H. Haenen (2007), De regels en het spel. Gesprekken met Morris Tabaksblat, Amsterdam: Business Contact.

Deakin, S. en S.J. Konzelmann (2003), Corporate governance after Enron: An age of enlightenment?, Organization, vol. 10, no. 3, pp. 583-587.

Denis, D.J., P. Hanouna, en A. Sarin (2006), Is there a dark side to incentive compensation?, Journal of Corporate Finance, vol. 12, no. 3 , pp. 467-488.

Desai, H., S. Krishnamurthy, en K. Venkataram (2004), Do short sellers target firms with poor earnings quality: evidence from earnings restatements, SSRN, http://papers.ssrn.com/sol3/papers. cfm?abstract_id=633283.

Efendi, J., A. Sristava, en E.P. Swanson (2007), Why Do Corporate Managers Misstate Financial Statements: The Role of Option Compensation, Corporate Governance and Other Factors, Journal of Financial Economics, vol. 85, no. 3, pp. 667-708.

European Corporate Governance Forum (2006), Statement of the European Corporate Governance Forum on the comply-or-explain principle, Brussel; zie: http://ec.europa.eu/internal_market/ company/ecgforum/index_en.htm.

Ferrarini, G. en P. Giudici (2005), Financial scandals and the role of private enforcement: the Parmalat case, ECGl Law Working Paper No,. 40/2005, SSRN, zie: http://papers.ssrn.com/sol3/papers. cfm?abstract_id $=730403$.

Griffin, P.A. (2002), A league of their own? Financial analysts' responses to restatements and corrective disclosures, SSRN; zie: http://papers. ssrn.com/sol3/papers.cfm?abstract_id=326581.

Huron Consulting Group, 2004 Annual Review of Financial Reporting Matters, 2005; zie: www.huronconsultinggroup.com/.

Mouthaan, E.H.J. (2006), De verantwoordelijkheden van de audit commissie, Maandblad voor Accountancy en Bedrijfseconomie, vol. 80, no. 3, maart, pp. 84-92.

Mouthaan, E.H.J. (2000), De verantwoordelijkheid voor het internal control system en het rapporteren terzake, proefschrift Universiteit Leiden, 2000.

Public Company Accounting Oversights Board (2007), Auditing Standard No. 5: An audit of internal control over financial reporting that is integrated with an audit of financial statements; zie: www.pcaobus.org/Standards/

Securities and Exchange Commission (2007), proposed rule, Management's report on internal control over financial reporting, release nr. 33-8762; en final rule, Amendments to rules regarding management's reports on internal control over financial reporting, release nr. 33-8809; zie: www.sec.gov/.

Singapore Government (1995), Report of the Inspectors of Barings
Futures (Singapore) Pte Ltd; voor executive summary, zie: http://www.sgrm.com/art41.htm

Skeel, D.A. (2005), Icarus and American Corporate Regulation, Business Lawyer, vol. 61, no. 1, pp. 155-177.

US General Accounting Office (GAO) (2006), Financial Restatements: Update of Public CompanyTrends, Market Impacts and Regulatory Responses, 2006; zie: www.gao.gov/new.items/d06678.pdf. 